\title{
REDES INSTITUCIONALES Y DESARROLLO ECONÓMICO EN CIUDADES PEQUEÑAS Y MEDIAS: EL CASO DE LA LOCALIDAD PUNTA ALTA
}

\author{
José Ignacio Diez (•) \\ Ezequiel Lencina (*.) \\ Claudia Pong $(\cdot \cdot)$ \\ Universidad Nacional del Sur
}

\begin{abstract}
RESUMEN
En las últimas décadas las ciudades de dimensión pequeño y medio han recuperado su protagonismo dentro de los sistemas urbanos, tanto en el ámbito científico como en las estrategias de ordenamiento y desarrollo territorial a escala internacional. Estas localidades están adquiriendo preponderancia como componentes destacados de las políticas regionales, incorporándose como actores claves en las posibilidades de despegue industrial de territorios periféricos. Entre los instrumentos tendientes a promover su crecimiento y consolidación, la literatura especializada destaca la conformación de redes institucionales, como un elemento capaz de incentivar la innovación y el cambio tecnológico. El presente trabajo pretende analizar la dinámica de funcionamiento de la red de organizaciones de apoyo a la producción (OAP's) de la localidad de Punta Alta (Argentina), con el propósito de entender en qué medida estas instituciones mejoran las condiciones de competencia y desarrollo del territorio.
\end{abstract}

\section{PALABRAS CLAVE:}

redes, desarrollo territorial, competitividad urbana, geografía económica.

\footnotetext{
(•)E-mail: jdiez@uns.edu.ar

(••)E-mail: ezequiel-lencina@hotmail.com

(․) E-mail: cpong@iiess-conicet.gob.ar
}

\section{ABSTRACT}

In the last decades small cities have recovered their importance in urban systems, both in the field of scientific literature as on the plane of development strategies in a world scale. this towns are acquiring preponderance as main components on regional development policies, being recognized as key actors on the stimulation of industrial possibilities for peripheral territories. Among the instruments aimed at promoting growth, the literature emphasizes the creation of institutional networks, as an element capable of encouraging innovation and technological change. This paper analyzes how the institutional networks operate in a small town called Punta Alta in Argentina, trying to understand the way in which these organizations can improve the competitive conditions and development possibilities of this territory.

\section{KEY WORDS :}

networks, territorial development, urban competitiveness, economic geography.

RECEPCIŌN : 20/10/17

ACEPTACIÓN FINAL: 14/03/18 


\section{IntRODUCCiōN}

En las últimas décadas las ciudades de dimensión pequeño y medio han recuperado su protagonismo dentro de los sistemas urbanos, tanto en el ámbito de la bibliografía científica como en las estrategias de ordenamiento y desarrollo territorial.

Al igual que lo sucedido en la década del '60, estas urbes están adquiriendo preponderancia como componentes destacados de las políticas de desarrollo regional, incorporándose como actores claves en las posibilidades de despegue industrial de territorios periféricos.

Históricamente estos núcleos urbanos fueron concebidos, en primer término, como centros de servicios dedicados a funciones terciarias de segundo nivel y en segundo lugar, como cabecera de industrias especializadas en sectores maduros, que podían ser dinamizados a través de diferentes iniciativas de origen público.

Las denominadas políticas de polarización (Perroux, 1955), destinadas a generar externalidades positivas y efectos de difusión, tuvieron a éstas localidades muchas veces como destinatarias, siendo beneficiadas con ayudas financieras, implantación de empresas o desgravaciones impositivas.

En la actualidad, el interés que surge por este tipo de ciudades se produce en un contexto muy diferente (globalización, crisis del estado de bienestar, 
cambios en los regímenes tecnológicos y de acumulación global), pero nuevamente se plantea la necesidad de conocer mejor su funcionamiento, para aplicar estrategias de desarrollo que favorezcan su crecimiento y consolidación.

Entre los instrumentos tendientes a promover estos objetivos, la literatura sobre economía urbana y regional destaca la conformación de redes institucionales, como un elemento capaz de incentivar la innovación, el cambio tecnológico y la acumulación de capital.

En este sentido, autores como Vázquez Barquero (2001) sostienen que "en las ciudades pequeñas y medias, la existencia de un tejido institucional denso y complejo ha sido determinante para garantizar una adecuada competitividad de base territorial».

De acuerdo a Camagni (1991) estas redes funcionan suministrando a las empresas capacidades faltantes, potenciando procesos de aprendizaje y realizando informalmente funciones de investigación, transmisión, selección, decodificación, transformación y control de la información que permiten la emergencia de ventajas cooperativas.

Según Méndez (1997), en los núcleos urbanos de esta naturaleza más dinámicos a nivel internacional las organizaciones territoriales son portadoras de recursos específicos que, combinados a través del espacio de las redes, generan ventajas competitivas capaces de aumentar su atractividad y fertilidad ${ }^{1}$, promoviendo de esta forma procesos de desarrollo económico local.

Por otro lado, en los territorios más rezagados el trabajo colaborativo entre las entidades locales es precario o no existe, situación que repercute sobre sus capacidades competitivas y sus niveles de innovación, afectando notablemente el ambiente económico y las decisiones de inversión.

El presente trabajo pretende analizar la dinámica de funcionamiento de la red de OAP's (organizaciones de apoyo a la producción) de la localidad de Punta Alta en Argentina, con el propósito de entender en qué medida estas instituciones apoyan u promueven el crecimiento económico y la acumulación de capital.

Por organizaciones de apoyo a la producción se entiende aquellas entidades que, en sus objetivos estatutarios, plantean alcances relacionados con el desarrollo productivo de la localidad y su zona de influencia; entre ellas puede citarse al gobierno local y los entes públicos no gubernamentales, las organizaciones gremiales empresarias y las instituciones educativas, entre otras.

La hipótesis que guía la presente investigación es que estas entidades no han logrado desarrollar una masa crítica de relaciones, proyectos y actividades, que les permita posicionarse como agentes relevantes en materia de promoción del desarrollo económico del distrito. 
Con el propósito de corroborar esta presunción, los autores realizaron entrevistas $^{2}$ a 14 OAP's entre los meses de mayo y noviembre de 2014. En las mismas se recolecto información concerniente a: i) Metas y objetivos organizacionales, ii) Trayectoria; iii) vínculos y relaciones entre las mismas, iv) Percepción de sus dirigentes respecto a diversos puntos relacionados con las posibilidades de desarrollo económico local. Para la selección de las instituciones a entrevistar se solicitó la colaboración de informantes claves, personas con un amplio conocimiento respecto a la vida económica e institucional de la localidad.

\section{ORGANIZACIÓN DEL TRABAJO}

En el presente artículo se describe, en primer término, el marco teórico que da sustento a la investigación. En esta sección se exponen los principales aportes de la literatura especializada respecto al papel de las ciudades pequeñas y medias en los procesos de desarrollo territorial. En su extensión se tratan de combinar las miradas de las dos disciplinas sociales que convergen en este estudio (Geografía y Economía), integrando elementos de la discusión teórica contemporánea sobre la cuestión urbana, el crecimiento económico y la acumulación de capital. Vale la pena señalar, sin embargo, que de ningún modo esta sección pretende ser una revisión exhaustiva de los múltiples aportes de estas disciplinas al entendimiento del fenómeno, sino un esfuerzo en la construcción de un esquema conceptual que resulta funcional a la presente investigación.

En segundo lugar, se enuncian algunos rasgos fundamentales de la teoría de las redes, poniendo especial énfasis en el papel que tienen las tramas organizacionales como desencadenantes de procesos de desarrollo económico territorial. En este apartado también se hace mención a las diferentes técnicas que existen para relevar información sobre la dinámica de funcionamiento de dichas tramas y se consideran los avances que han existido hasta la fecha en el estudio de esta problemática en Argentina.

En tercer lugar, se realiza una breve presentación del territorio objeto de estudio. Aquí también se menciona en forma sucinta el proceso de gestación de las principales organizaciones del distrito y luego se analiza la comunicación existente entre las mismas. A lo largo de este punto, el esfuerzo de investigación se focaliza en esquematizar los procesos de intercambio de conocimientos e información entre actores, por considerarlos insumo fundamental para el desarrollo de cualquier territorio. Posteriormente, se consideran diferentes medidas de análisis de redes sociales (densidad, grado de centralidad, centralidad de cercanía y grado 
de intermediación) con el propósito de evaluar estos procesos de comunicación; estas medidas surgen de la utilización de software especializado a tal efecto ${ }^{3}$.

Esta forma de evaluación de redes, muy utilizada en el ámbito de la antropología social y la sociología, ha ido ganando terreno en los estudios sobre desarrollo económico territorial, principalmente debido a la facilidad que presenta para considerar diferentes niveles análisis: meso (o de estudio de la trama en su conjunto) y micro (o de posición de cada actor en el contexto de la red). Las medidas que se presentan en el trabajo constituyen una aproximación idónea para el entendimiento de estos dos enfoques.

En quinto término, el artículo muestra cómo el proceso de comunicación vigente en Punta Alta se traduce o no en actividades más complejas, como son los proyectos económicos conjuntos, los cuales tienen incidencia sobre el crecimiento y la acumulación de capital a escala local.

Posteriormente, se exhiben algunos resultados respecto a la presencia/ausencia de liderazgos dentro del sistema institucional de la jurisdicción, con el propósito de entender la capacidad que registra la trama en general y algunos actores en particular para promover esfuerzos concertados. En este punto, la metodología utilizada se encuentra en línea con diversos trabajos desarrollados por Comisión Económica para América Latina y el Caribe (CEPAL) para distintas localidades de Argentina ${ }^{4}$.

Por último, a modo de conclusión, se presenta un análisis pormenorizado de los indicadores construidos y de los datos relevados, considerando tanto los resultados en términos sistémicos como aquellos que involucran a los actores centrales del entramado analizado.

\section{CIUDADES PEQUEÑAS Y MEDIAS: COMPETITIVIDAD Y DESARROLLO TERRITORIAL}

En el mundo actual, hacer mención a la ciudad pequeña o media implica hablar de un espacio que puede estar relacionado en forma activa con el resto del mundo, pero con un entorno social, cultural, simbólico y morfológico particular. En este contexto de avance sistemático de la urbanización a escala planetaria, el significado de las ciudades pequeñas y medias cambia respecto a lo que sucedía en el pasado 5 .

Anteriormente, en el ámbito de la geografía y de la planificación urbana se veía a la creciente urbanización como algo positivo hasta que, desde inicios de los años '70, la teoría de los límites del crecimiento (Meadows et al., 1972) ${ }^{6}$ altero esta perspectiva. Los problemas de polución, las deseconomías de aglomera- 
ción en servicios públicos y equipamiento, las crecientes migraciones internas y el despoblamiento del territorio, etc. hicieron reflexionar a los planificadores respecto a la necesidad de buscar un desarrollo urbano más equilibrado ${ }^{7}$.

Ante esta situación, se produce una revalorización de las virtudes o ventajas de las ciudades pequeñas y medias y su rol de articuladoras y dinamizadoras del desarrollo regional.

Históricamente, estos núcleos poblacionales funcionaron como centros administrativos, espacios concentradores para la provisión de servicios y como centros para la comercialización y venta de productos necesarios para la producción agrícola (Capel, 2009).

Posteriormente, luego de la revolución industrial, muchas de estas localidades se transformaron en espacios de radicación de empresas especializadas en sectores de maduros, como por ejemplo la industria del textil y de calzado. A su vez, durante la década del ' 60 algunas fueron objeto de diversas políticas que buscaron su crecimiento y consolidación a través de subsidios, créditos e inversión pública, alterando su dinámica, morfología y funcionamiento mediante lo que se conoció como la política de polos de crecimiento (Paelinck, 1963 y Boudeville, 1965).

Sin embargo, hasta entrados los años ' 80 , las ventajas económicas de la gran ciudad en relación a los núcleos urbanos de menor tamaño relativo eran muy significativas: externalidades positivas de todo tipo vinculadas a la cercanía, a la posibilidad de establecer mayor cantidad de relaciones sociales, a la educación, a la disponibilidad de centros científicos y a la variedad del mercado trabajo.

Hoy en día, motivo de la creciente internacionalización de las telecomunicaciones y del desarrollo masivo de los medios de transporte, estas ventajas parecen estar disminuyendo, ya que la mayor conectividad mejora notablemente las capacidades competitivas de las ciudades medias y pequeñas.

En este sentido, estos espacios se constituyen no solamente en ámbitos propicios para el buen vivir, sino también en lugares adecuados para el desarrollo de emprendimientos productivos de cierta envergadura.

Por otro lado, una utilización más adecuada de los recursos económicos, sociales, culturales y técnicos de estas sociedades, también estaría permitiendo acortar la brecha competitiva ${ }^{8}$.

Entre los instrumentos que permiten la optimización de estos recursos endógenos se encuentran las redes institucionales.

La literatura sobre desarrollo económico territorial destaca el papel que tienen estas tramas de colaboración en la difusión de conocimientos e información y en la consolidación de estrategias de aprendizaje colectivo que repercuten positivamente sobre las potencialidades económicas del territorio. 


\section{LAS ORGANIZACIONES, LAS REDES Y LA COMPETITIVIDAD TERRITORIAL}

\subsection{LA PERSPECTIVA TEÓRICA DEL ANÁLISIS DE REDES}

Como se sostuvo en la introducción de la presente investigación, en la actualidad una parte sustancial de los estudios sobre desarrollo económico local destacan el papel de las redes como un elemento clave para alcanzar una utilización óptima de los factores productivos.

Según Méndez (1998), una porción importante del éxito competitivo de diversas localidades de tamaño pequeño y medio en el escenario de la economía mundial está íntimamente ligado al uso que estas sociedades hacen de los recursos genéricos y específicos presentes en el territorio.

Bajo este criterio, se entiende por recursos genéricos aquellos factores indiferenciados que existen en la mayor parte de los lugares (recursos naturales, población sin calificación, ahorro disponible para inversión, etc.), mientras que por recursos específicos se consideran a aquellos que se construyen a partir del propio proceso de crecimiento económico y desarrollo (infraestructuras tecnológicas, mano de obra calificada, cultura organizacional y capacidad de gestión, etc.).

Bajo esta óptica, el espacio de las redes y de la acción colectiva permite optimizar la utilización de ambos factores, movilizando recursos que se encuentran subutilizados y/o estableciendo diferentes combinaciones de los mismos, que se traducen a posteriori en una mayor acumulación de capital.

A través de las iniciativas conjuntas, los actores locales se comunican, compartiendo conocimientos y capacidades y construyendo espacios de trabajo común que facilitan el desarrollo de proyectos e innovaciones.

En este sentido, los beneficios de la cooperación son múltiples, ya que el trabajo conjunto permite enfrentar problemas complejos que serían imposibles de abordar por un solo actor. De acuerdo a Harrigan (1992), las ventajas de la cooperación son las siguientes:

a) Beneficios internos: las acciones conjuntas permiten que los agentes compartan riesgos, accedan a mejor información y eviten la duplicación de esfuerzos.

b) Beneficios competitivos: la colaboración entre diversos agentes constituye un instrumento eficaz para promover sectores industriales específicos, permitiendo alcanzar un mejor posicionamiento de los mismos en la economía mundial. c) Beneficios estratégicos: la cooperación promueve la sinergia entre diversos actores, la transferencia de conocimientos y tecnología y amplía las posibilidades de diversificación de las actividades productivas. 
En el caso particular de las redes institucionales, su conformación generalmente apunta al suministro de bienes públicos (planes estratégicos, agendas de desarrollo, etc.) que de otra forma no se prestarían.

En este sentido, la conformación de tramas organizacionales constituye un medio para la resolución de problemas de tipo (para) políticos, es decir casos de búsqueda colectiva de objetivos o realización de propósitos comunes.

De acuerdo a Michael Best (1990), los sistemas de redes permiten diseñar mecanismos de governance dentro de un territorio, que facilitan los procesos de competencia de tipo schumpeteriano, donde la innovación y la creación de mercados resultan fundamentales para el crecimiento económico.

En términos del autor, a través del espacio de las redes, las organizaciones del medio pueden comunicarse y coordinar acciones que redundan a posteriori en una mayor acumulación de capital. Este tipo de vínculos incluye la realización de proyectos de colaboración en áreas productivas, científicas, de prestación de servicios, institucionales, de infraestructura y equipamiento.

A modo de ejemplo sobre los alcances de este tipo de vínculos, en un trabajo sobre 33 localidades de tamaño pequeño y medio de la Unión Europea, Bennett y Krebs (1994) encontraron que el papel del estado resulta fundamental en la coordinación y consolidación de las redes, siendo las ciudades más exitosas aquellas que lograron crear una estructura estable de gobernabilidad local.

En este sentido, los autores notan que la complejidad de las mismas co-varia con el grado de desarrollo económico: las ciudades estancadas o en proceso de declive tienen redes fragmentadas y con una configuración de mosaico, mientras que aquellas "ganadoras" presentan múltiples conexiones entre los diferentes actores.

En relación a este punto, los trabajos empíricos sobre la temática muestran que el paso de un modelo de organización del territorio de carácter desarticulado y jerárquico hacia un modelo en forma de red, requiere contar con instituciones dotadas de ciertos umbrales mínimos de recursos humanos y técnicos, que les permita a éstas administrar la complejidad. A estos recursos de carácter tangible, deben sumarse necesariamente aspectos idiosincráticos y culturales que favorezcan el diálogo y la interacción.

En esta línea argumental, Boisier (1997) sostiene que existen cuatro características básicas que definen a un institución capaz de trabajar en forma reticular: la velocidad para reaccionar frente a cambios rápidos en el entorno, la flexibilidad que posibilita dar respuestas diversas (de grande o pequeña escala, coyunturales o estructurales, etc.) de acuerdo a las demandas del exterior, la virtualidad como condición para hacer arreglos de cooperación en el espacio 
cibernético y la inteligencia, definida como la capacidad para aprender de la propia experiencia que surge en la relación con el otro.

Sobre esta última cuestión, Morgan (1986) plantea que las organizaciones pueden ser asemejadas a sistemas de procesamiento de información, que atrapan y filtran los conocimientos que circulan en el entorno, los procesan en términos de lo que han aprendido, los interpretan, los cambian y actúan sobre ellos.

\subsection{EL TRATAMIENTO EMPÍRICO DEL FENÓMENO DE LAS TRAMAS ORGANIZACIONALES}

En cuanto a la metodología utilizada para el estudio de redes institucionales, las investigaciones referidas a esta problemática comienzan por identificar las organizaciones de apoyo a la producción más activas en un territorio concreto, evaluando sus objetivos y alcances.

Posteriormente, intentan interpretar los lazos que unen a las distintas organizaciones, diferenciando la mera transmisión de información entre las partes de aquellos vínculos que suponen un grado de compromiso mayor entre los agentes (Filippi y Torre, 2003).

En lo que respecta específicamente al análisis de la estructura de la red, los diferentes trabajos incorporan tanto aproximaciones de tipo cuantitativas como cualitativas que ayudan a su mejor caracterización.

Respecto a los enfoques de tipo cuantitativo, la medición de la densidad reticular es el aspecto más estudiado y consiste en identificar la existencia o no de vínculos entre los actores, de tal forma de evaluar el grado de conectividad vigente en el conjunto considerado.

La utilización de cualquiera de los índices creados para tal fin, resulta útil para conocer el grado de saturación presente en una red, permitiendo comparar entramados organizacionales correspondientes a distintos ámbitos territoriales y su evolución, apreciando su grado de consolidación y madurez a través del tiempo (Caravaca et al., 2005).

A este tipo de índices suele agregársele información relativa a la cercanía y centralidad de los agentes, conjuntamente con indicadores que consideran la capacidad de mediación en los procesos de comunicación registrados entre los diferentes actores.

En cuanto a la caracterización cualitativa de las redes, los trabajos se focalizan en considerar las propiedades de las relaciones de cooperación entre los agentes, la existencia de una correcta definición de las estructuras de poder y la capacidad de movilización colectiva.

En el análisis de las propiedades de la trama, se diferencia entre aquellas de carácter reactivo, que surgen ante la necesidad de responder a problemas 
ya existentes y las de carácter proactivo, que buscan descubrir nuevas oportunidades (Méndez, 1998).

En este punto, también es importante considerar la coyunturalidad o estabilidad de la cooperación y la existencia o no de una reflexión estratégica que oriente la misma a mediano o largo plazo (Domínguez Ares, 1999; Erbiti, 2004).

Por su parte, la caracterización de las estructuras de poder supone analizar el equilibrio o la hegemonía de los agentes y la posible conflictividad o no que pueda originarse entre ellos (Hanneman, 1998).

\subsection{LAS REDES INST ITUCIONALES EN CIUDADES PEQUEÑAS Y MEDIAS DE ARGENTINA}

Las investigaciones sobre redes institucionales en ciudades pequeñas y medias en Argentina son relativamente recientes. Sus orígenes datan de la década del 2000, cuando el gobierno argentino encarga a la CEPAL estudiar la potencialidad económica de algunos núcleos urbanos del interior y en ese marco plantea la necesidad de analizar el comportamiento de las organizaciones económicas del territorio.

Por aquel entonces, los hacedores de política pública del gobierno argentino buscaban reproducir en localidades pequeñas y medias aquellos rasgos virtuosos que habían garantizado el éxito económico de distintas ciudades europeas, fundamentalmente de aquellas correspondientes al mezzogiorno italiano.

De este modo, influenciados por la política de desarrollo territorial de la Comunidad Europea y por el enfoque de los distritos industriales italianos, el gobierno argentino impulsa diagnósticos institucionales sobre las localidades de Rafaela (Ferraro y Costamagna, 2000), Tandil (D’Annunzio, 2000) y Mar del Plata (Ferraro y Costamagna, 2002).

Posteriormente, investigadores ligados al estudio de la economía urbana y regional interesados en esta problemática, extienden los estudios de caso a otras localidades de distinto tamaño relativo, fundamentalmente (aunque no únicamente) de la pampa húmeda: Bragado (Costmagna, Ferraro y Gor, 2006) Tres Arroyos (Martín, 2007), Bahía Blanca (Diez, 2010) y Pigué (Diez y Urtizberea, 2015) entre los más relevantes.

Si bien hasta la fecha no existe ningún estudio que sinteticen adecuadamente los principales resultados de estas experiencias, si hay algunos rasgos comunes presentes en ellos que permiten establecer cierta caracterización. En términos generales, se ha observado un bajo grado de interacción entre los actores y un bajo involucramiento de ellos con las problemáticas ligadas al desarrollo del territorio (Costamagna, 2008). 


\section{PUNTA ALTA: CARACTERÍSTICAS GENERALES Y ENTRAMAdO INSTITUCIONAL}

La localidad de Punta Alta es la cabecera de la Jurisdicción de Coronel Rosales en el sudoeste de la provincia de Buenos Aires. Cuenta con 62.152 habitantes (INDEC, 2010), constituye una ciudad-puerto y es sede de dos dependencias estratégicas para la defensa Argentina: la base naval Puerto Belgrano y la base de Infantería Naval Baterías (Mapa 1).

\section{Mapa 1.}

Ubicación geográfica de la localidad de Punta Alta

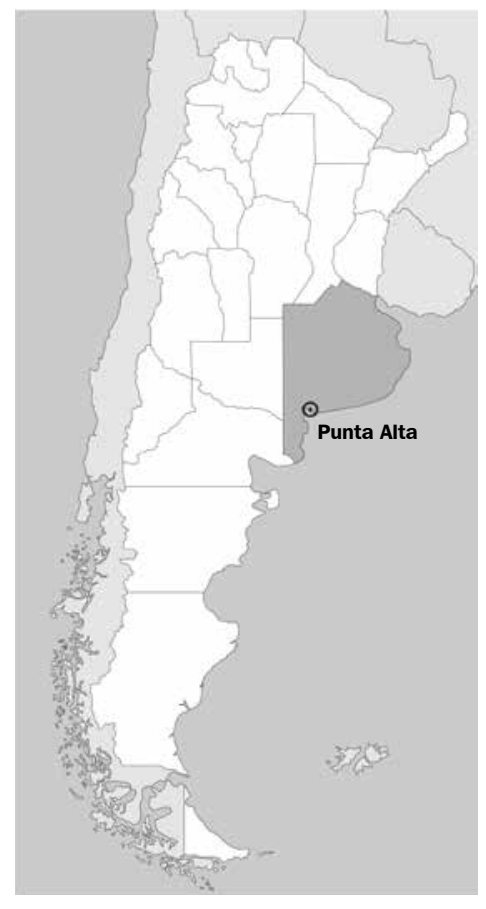

Históricamente, el crecimiento de la ciudad estuvo ligado a dos elementos claves que actuaron como dinamizadores de la economía local: la inversión del estado en la conformación del arsenal marítimo de guerra y la actividad portuaria, ligada a la exportación de trigo y a otras commodities de origen agropecuario.

Estos dos factores dinámicos, permitieron que en el transcurso de los años se erija en Punta Alta una pequeña burguesía local. La misma se especializa 
en la prestación de servicios, la actividad comercial y la industria de carácter artesanal. Todas ellas apuntan a satisfacer mayormente las necesidades de la población local, del enclave naval-militar y de la actividad portuaria.

Hoy en día el PBG (Producto Bruto Geográfico) de la jurisdicción asciende a 321.549 millones de pesos, lo que equivale al 0,3\% del Producto Bruto Provincial. El sector económico más importante del distrito es el de Servicios Inmobiliarios, empresariales y de Alquiler, el cual alcanza los 71.517 millones de pesos, que equivalen al $22 \%$ del PBG total.

Lo siguen en orden de importancia Transporte, Almacenamiento y Comunicaciones con 49.005 millones de pesos (15,20\% del PBG) y Comercio al por mayor, menor y reparaciones con 47.911 millones de pesos $(14,90 \%$ del PBG) respectivamente. Esto se observa en el Cuadro 1.

\section{Cuadro 1.}

Producto bruto geográfico partido de Coronel Rosales a precios del 2003

Sector de actividad económica

A Agricultura, ganadería, caza y silvicultura

B Pesca y servicios conexos

C Explotación de minas y canteras

D Industria Manufacturera

E Electricidad, gas y agua

F Construcción

G Comercio al por mayor, al por menor y reparaciones

H Hoteles y restaurantes

I Transporte, almacenamiento y comunicaciones

J Intermediación financiera y otros servicios financieros

K Servicios inmobiliarios, empresariales y de alquiler

L Administración pública, defensa y seguridad social obligatoria

M Enseñanza

N Servicios sociales y de salud

- Servicios comunitarios, sociales y personales n.c.p.

P Servicios de hogares privados que contratan servicio doméstico

Total

Fuente: Dirección Provincial de Estadística de la Provincia de Buenos Aires
Miles de \$ Participación

\begin{tabular}{rr}
22.242 & $6,90 \%$ \\
233 & $0,10 \%$ \\
0 & $0,00 \%$ \\
22.323 & $6,90 \%$ \\
15.465 & $4,80 \%$ \\
16.075 & $5,00 \%$ \\
47.911 & $14,90 \%$ \\
10.294 & $3,20 \%$ \\
49.005 & $15,20 \%$ \\
13.674 & $4,30 \%$ \\
71.517 & $22,20 \%$ \\
6.264 & $1,90 \%$ \\
22.444 & $7,00 \%$ \\
10.089 & $3,10 \%$ \\
9.456 & $2,90 \%$ \\
4.556 & $1,40 \%$ \\
\hline
\end{tabular}

321.549 
En cuanto al entramado institucional, su crecimiento y expansión ha ido en paralelo al desenvolvimiento económico distrital, surgiendo inicialmente las entidades vinculadas al sector público, a la actividad naval y los servicios, luego las cámaras empresarias, la banca y finalmente las entidades educativas (Cuadro 2).

\section{Cuadro 2.}

Organizaciones de apoyo a la producción de Punta Alta

\begin{tabular}{|c|c|}
\hline Tipo de organización & Nombre de la entidad \\
\hline \multirow[t]{3}{*}{ Gobierno Local y Entes Públicos } & Municipalidad de Coronel Rosales (MUNI) \\
\hline & Base Naval Puerto Belgrano (BaseNaval) \\
\hline & Ente Zona Franca Bahía Blanca Coronel Rosales (EZFBBCR) \\
\hline \multirow[t]{4}{*}{ Instituciones Educativas } & Centro de Formación Profesional René Favaloro (CPFav) \\
\hline & Escuela de Enseñanza Técnica №1 (ET Nº 1) \\
\hline & Instituto de Formación Docente № 79 (ISFD № 79) \\
\hline & Escuela de Suboficiales de la Armada Argentina (ESA) \\
\hline \multirow[t]{2}{*}{ Banca Pública y de Fomento } & Banco de la Nación Argentina (BcoNACION) \\
\hline & Banco de la Provincia de Buenos Aires (BcoPCIA) \\
\hline \multirow[t]{4}{*}{ Cámaras Empresarias } & Unión del comercio, la industria y el agro de Punta Alta (UCIAPA) \\
\hline & Cámara de Mujeres Empresarias (CMempres) \\
\hline & Cámara de Pescadores \\
\hline & Cámara de Talleres Navales (CTNaval) \\
\hline Otras organizaciones & Cooperativa Eléctrica de Punta Alta (CoopElect-CEPA) \\
\hline
\end{tabular}

Fuente: Elaboración propia en base a entrevistas.

Pese a la existencia de una importante densidad de organizaciones, no existen en la localidad estudios que se hayan focalizado en conocer su dinámica, comportamiento e incidencia en los procesos de desarrollo económico del territorio. En este sentido, no hay evidencia respecto a si las entidades han presentado una importante trayectoria de colaboración a favor del crecimiento económico de Punta Alta y su zona de influencia, por lo que no se contó con antecedentes relevantes que sirvieran de base a la presente investigación.

Sin embargo, a partir de las entrevistas realizadas en este estudio, pudo corroborarse que hoy en día las instituciones no presentan un importante nivel de comunicación, ya que existen tan sólo un 31\% de los vínculos posibles entre sí (Figura 1). 


\section{Figura 1.}

Comunicación efectiva entre las organizaciones de apoyo a la producción

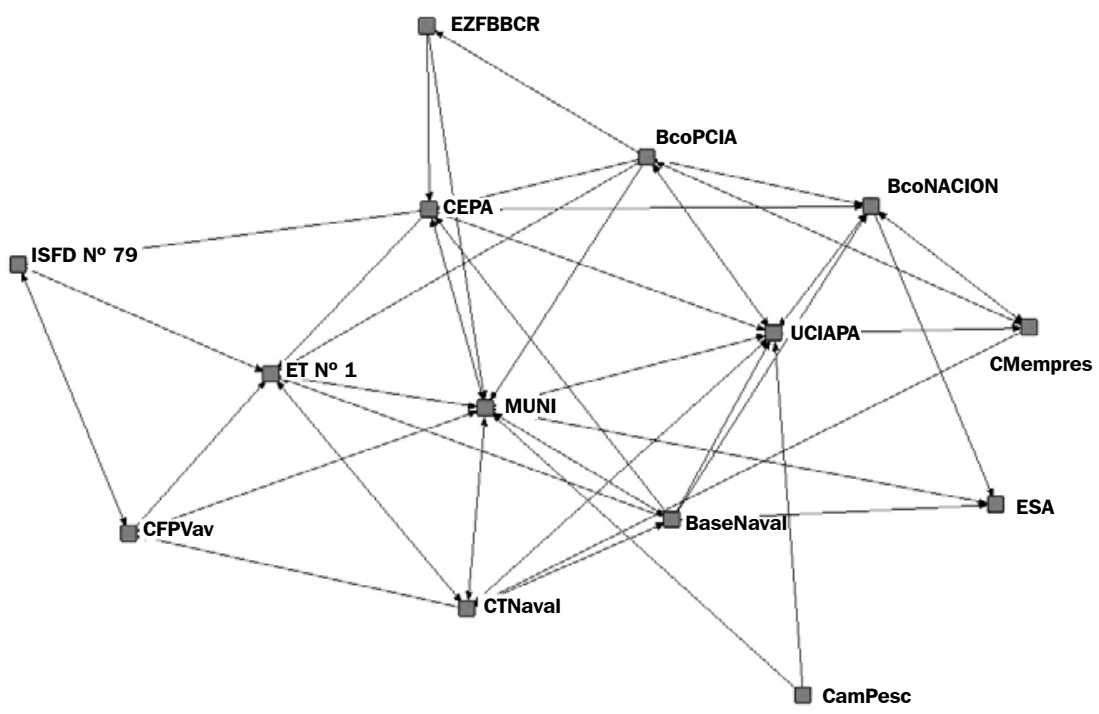

Fuente: elaboración propia en base a UCINET y NETDRAW.

Esto implica un número importante de orificios estructurales en la red de comunicaciones. A continuación, se presenta un análisis pormenorizado de dicha trama, a través de diversos indicadores: grado de centralidad, centralidad de cercanía y grado de intermediación.

- Grado de Centralidad

El grado de centralidad muestra la cantidad de actores a los cuales una organización está directamente unido; es decir que si una entidad tiene un mayor número de vínculos, ésta se posiciona en una condición ventajosa, ya que puede acceder a mayor cantidad de conocimientos e información, satisfaciendo de esta manera, un mayor número de necesidades. 


\section{Cuadro 3.}

Grado de centralidad de la red comunicaciones

\begin{tabular}{llccc}
\hline & $\begin{array}{l}\text { Lazos } \\
\text { de salida }\end{array}$ & $\begin{array}{l}\text { Lazos } \\
\text { de entrada }\end{array}$ & $\begin{array}{l}\text { Normal lazo } \\
\text { de salida }\end{array}$ & $\begin{array}{l}\text { Normal lazo } \\
\text { de entrada }\end{array}$ \\
\hline BcoPCIA & 7.000 & 3.000 & 53.846 & 23.077 \\
BaseNaval & 7.000 & 3.000 & 53.846 & 23.077 \\
MUNI & 6.000 & 10.000 & 46.154 & 76.923 \\
CTNaval & 5.000 & 5.000 & 38.462 & 38.462 \\
BcoNACION & 5.000 & 5.000 & 38.462 & 38.462 \\
UCIAPA & 5.000 & 8.000 & 38.462 & 61.538 \\
CEPA & 5.000 & 5.000 & 38.462 & 38.462 \\
CMempres & 4.000 & 3.000 & 30.769 & 23.077 \\
CFPFav & 3.000 & 3.000 & 23.077 & 23.077 \\
ESA & 2.000 & 3.000 & 15.385 & 23.077 \\
ET No 1 & 2.000 & 6.000 & 15.385 & 46.154 \\
CamPesc & 2.000 & 0.000 & 15.385 & 0.000 \\
EZFBBCR & 2.000 & 1.000 & 15.385 & 7.692 \\
ISFD N ${ }^{\circ}$ 79 & 2.000 & 2.000 & 15.385 & 15.385 \\
\hline
\end{tabular}

Fuente: elaboración propia en base a UCINET

Analizando el Cuadro 3, se puede observar que tanto el Banco Provincia (BcoPCIA) como la Base Naval (BaseNaval) son las entidades que más información envían, con un valor de 7 vínculos de salida.

En orden de importancia, le siguen la Municipalidad (MUNI) con 6 vínculos y luego, CTNaval, BcoNACION, UCIAPA y CEPA con 5 lazos respectivamente.

Estas organizaciones son las más importantes o influyentes en el esquema de relaciones, ya que están en condiciones de diseminar más datos e información a lo largo de la trama.

Con respecto a los grados de entrada (u organizaciones que más reciben información), se encuentran la municipalidad (MUNI) que lidera el indicador, seguida por UCIAPA y la Escuela de Enseñanza Técnica No 1 (ET No 1), con valores de 10, 8 y 6 lazos de entrada respectivamente.

Este último grupo de actores puede considerarse como prestigioso o prominente dentro de la red, y por ende, el intento por parte del resto de los agentes de compartir conocimientos con ellos puede ser interpretado como un acto de deferencia o reconocimiento de sus posiciones privilegiadas en la trama de relaciones. 


\section{Cuadro 4.}

Estadísticas descriptivas nivel meso y macro de la red

\begin{tabular}{lrrrr}
\hline & $\begin{array}{l}\text { Lazos } \\
\text { de salida }\end{array}$ & \multicolumn{1}{l}{$\begin{array}{l}\text { Lazos } \\
\text { de entrada }\end{array}$} & \multicolumn{1}{l}{$\begin{array}{l}\text { Normal lazos } \\
\text { de salida }\end{array}$} & \multicolumn{1}{l}{$\begin{array}{l}\text { Normal lazos } \\
\text { de entrada }\end{array}$} \\
\hline Promedio & 4.071 & 4.071 & 31.319 & 31.319 \\
Desvío Estándar & 1.831 & 2.576 & 14.084 & 19.818 \\
Suma & 57.000 & 57.000 & 438.462 & 438.462 \\
Varianza & 3.352 & 6.638 & 198.346 & 392.767 \\
SSQ & 279.000 & 325.000 & 16.508 .877 & 19.230 .770 \\
MCSSQ & 46.929 & 92.929 & 2.776 .839 & 5.498 .732 \\
EucNorm & 16.703 & 18.028 & 128.487 & 138.675 \\
Mínimo & 2.000 & 0.000 & 15.385 & 0.000 \\
Máximo & 7.000 & 10.000 & 53.846 & 76.923 \\
No $^{\circ}$ of Obs & 14.000 & 14.000 & 14.000 & 14.000 \\
\hline
\end{tabular}

Fuente: elaboración propia en base a UCINET

De acuerdo a la información suministrada en el Cuadro 4, puede apreciarse que en promedio las organizaciones mantienen un total de 4 lazos de entrada y salida, lo que refleja la existencia de bajos niveles de interacción.

Conjuntamente, se puede observar que los datos promedios no son homogéneos, dado que el desvío estándar difiere en lo que respecta a los lazos de salida y de entrada (1,8 y 2,5 respectivamente).

La información recopilada sobre los lazos máximos y mínimos refuerza la idea de heterogeneidad de la red; esto se ve reflejado en la fluctuación presente en los lazos de entrada (oscilando valores entre 0 y 10 ) y de salida (oscilando valores entre 2 y 7 ).

Por último, las medidas de centralización de grafo de Freeman refuerzan nuevamente la idea de heterogeneidad, registrando valores significativos de concentración por lazos de entrada (53\%) y no así en el caso de los lazos de salida, donde no parecen existir numerosos actores centrales.

- Centralidad de Cercanía

La medida grado de centralidad muestra sólo los vínculos inmediatos o lazos directos que tiene cada actor y no considera los contactos que una organización puede establecer en forma indirecta, es decir, aquellos que se producen utilizando otro actor como puente. Esta última tipología de contacto resulta 
de importancia en la medida que los agentes hacen circular información o conocimientos de terceros por el ámbito de la red.

El enfoque de centralidad de cercanía ${ }^{9}$, a diferencia de la medida grado de centralidad, no enfatiza la naturaleza del vínculo que une a los actores sino que hace hincapié en la distancia de un actor a otro, concentrándose en la distancia geodésica, es decir, la ruta más corta que un agente debe seguir para llegar a otro nodo.

Los datos analizados en el Cuadro 5, muestran como MUNI, UCIAPA y ET №1, son los actores más cercanos por grados de entrada (recepción de información); estos tres agentes están presentes en 81, 68 y 61 caminos geodésicos respectivamente.

En lo que respecta a la cercanía por lazos de salida, aparece en primer término la Cámara de Pescadores (Campesc), seguido en segundo lugar de BcoPCIA y BaseNaval respectivamente. En cuarto término aparece el actor MUNI presente en 39 caminos geodésicos.

\section{Cuadro 5.}

Centralidad de cercanía de la red comunicaciones

\begin{tabular}{lcc}
\hline & Cercanía de entrada & Cercanía de salida \\
\hline MUNI & 81.250 & 39.394 \\
UCIAPA & 68.421 & 38.235 \\
ET N $^{\circ} \mathbf{1}$ & 61.905 & 30.952 \\
CTNaval & 61.905 & 38.235 \\
CEPA & 59.091 & 38.235 \\
ESA & 54.167 & 31.707 \\
BaseNaval & 54.167 & 40.625 \\
CFPFav & 54.167 & 32.500 \\
BcoNACION & 52.000 & 38.235 \\
BCoPCIA & 44.828 & 41.935 \\
ISFD N ${ }^{\circ}$ 79 & 44.828 & 26.531 \\
CMempres & 44.828 & 37.143 \\
EZFBBCR & 33.333 & 34.211 \\
CamPesc & 7.143 & 48.148 \\
\hline
\end{tabular}

Fuente: elaboración propia en base a UCINET 
En cuanto al análisis de las estadísticas descriptivas sobre la centralidad de cercanía de la red, en el Cuadro 6 podemos apreciar que el promedio de cercanía por lazo de entrada es de 51 caminos geodésicos y el de salida resulta de 36 , siendo los valores máximos 81 y 48 respectivamente.

\section{Cuadro 6.}

Estadísticas sobre el nivel meso de la red

\begin{tabular}{lrr}
\hline & Cercanía de entrada & Cercanía de salida \\
\hline Promedio & 51.574 & 36.863 \\
Desvío Estándar & 16.687 & 5.180 \\
Suma & 722.030 & 516.087 \\
Varianza & 278.441 & 26.829 \\
SSQ & 41.135 .891 & 19.400 .332 \\
MCSSQ & 3.898 .179 & 375.600 \\
EucNorm & 202.820 & 139.285 \\
Mínimo & 7.143 & 26.531 \\
Máximo & 81.250 & 48.148 \\
N of Obs & 14.000 & 14.000 \\
\hline
\end{tabular}

Fuente: elaboración propia en base a UCINET

- Grado de intermediación

La importancia que un actor tiene en una red puede deberse a su capacidad para controlar la comunicación entre las diversas organizaciones.

La medida de grado de intermediación intenta captar este fenómeno, considerando todos los caminos geodésicos posibles entre los pares de nodos existentes en la red. El Cuadro 7 muestra la información correspondiente a la capacidad de intermediación de los principales agentes. 


\section{Cuadro 7.}

Grados de Intermediación de las Organizaciones

\begin{tabular}{lcc}
\hline & Intermediación & Normal de Intermediación \\
\hline MUNI & 45.738 & 29.319 \\
UCIAPA & 30.061 & 19.270 \\
BcoPCIA & 15.760 & 10.102 \\
CEPA & 13.669 & 8.762 \\
CTNaval & 11.886 & 7.619 \\
BaseNaval & 9.192 & 5.892 \\
BcoNACION & 8.533 & 5.470 \\
CFPFav & 7.692 & 4.931 \\
ET N 1 & 7.542 & 4.834 \\
ESA & 1.393 & 0.893 \\
CMempres & 0.893 & 0.572 \\
ISFD N 79 & 0.643 & 0.412 \\
CamPesc & 0.000 & 0.000 \\
EZFBBCR & 0.000 & 0.000 \\
\hline
\end{tabular}

Fuente: elaboración propia en base a UCINET

De acuerdo a lo observado en el Cuadro 7, el actor con mayor grado de intermediación es la Municipalidad (MUNI) presente en 45 caminos geodésicos, seguidos por UCIAPA y el Banco Provincia (BcoPCIA).

En términos porcentuales, existe un claro predominio del Municipio (MUNI), quien controla el $29 \%$ de la comunicación que circula a lo largo de la red, seguida por UCIAPA con $19 \%$ y el BcoPCIA con 10\% respectivamente.

Esta situación muestra una importante capacidad de estos actores para controlar la diseminación de conocimiento e información, permitiendo que estos agentes actúen como intermediarios o facilitadores de la comunicación con agentes alejados. 


\section{Cuadro 8.}

Estadísticas del nivel meso y macro de la red

\begin{tabular}{lcc}
\hline & Intermediación & Normal de Intermediación \\
\hline Promedio & 10.929 & 7.005 \\
Desvío Estándar & 12.469 & 7.993 \\
Suma & 153.000 & 98.077 \\
Varianza & 155.466 & 63.883 \\
SSQ & 3.848 .589 & 1.581 .439 \\
MCSSQ & 2.176 .518 & 894.361 \\
EucNorm & 62.037 & 39.767 \\
Mínimo & 0.000 & 0.000 \\
Máximo & 45.738 & 29.319 \\
$\mathbf{N}^{\circ}$ de Obs & 14.000 & 14.000 \\
\hline
\end{tabular}

Fuente: elaboración propia en base a UCINET

Centralidad de intermediación: 24\%

Por otro lado, en lo que respecta a las estadísticas descriptivas sobre intermediación presentes en el Cuadro $\mathrm{N}^{\circ} 8$, se puede apreciar que el promedio por actor es de 10 caminos geodésicos, valor que puede considerarse bajo, existiendo una importante variabilidad (desvío estándar igual a 12) con valores mínimo y máximo, de 0 y 45 respectivamente. Asimismo, el grado de centralidad de la red es poco significativo, siendo este del $24 \%$. Esto indica que, en su conjunto, no existe una importante capacidad de intermediación en el sistema y que este se concentra mayormente en dos/tres actores.

\section{PROYECTOS CONJUNTOS ENTRE ORGANIZACIONES DE PUNTA ALTA}

El establecimiento de un proyecto conjunto entre dos o más organizaciones, constituye un estadio superior de comunicación entre las mismas.

A través de un proyecto conjunto, las organizaciones profundizan lazos y compromisos y desarrollan una mayor capacidad para incidir sobre las posibilidades de desarrollo del territorio.

Para la definición de proyecto conjunto se adoptó la planteada por Diez (2010) en base a CEPAL-ILPES (1966), quien sostiene que existe un proyecto económico conjunto entre dos o más organizaciones cuando las mismas 
realizan acciones tendientes al logro de un objetivo común que propugna el desarrollo económico.

Desde su punto de vista, este accionar implica el uso y consumo de recursos escasos (ahorro, divisas, talento especializado, etc.) sacrificando beneficios actuales y asegurados, con el propósito de obtener a futuro beneficios conjuntos, que resultarán ser superiores a los individuales.

De esta manera, se consigue desarrollar acciones dirigidas a maximizar los consensos, racionalizando la administración de los disensos, de forma tal que los esfuerzos se muevan de forma unidireccional, siempre teniendo en cuenta el concepto de integración.

Dentro de la clasificación de proyectos económicos, el ILPES distingue categorías, subcategorías y clases de proyectos ${ }^{10}$. A continuación en el Cuadro 9 se detallan aquellos informados por las organizaciones entrevistadas:

\section{Cuadro 9.}

Proyectos relevados, organizaciones, intervinientes, tipo y características

\begin{tabular}{|c|c|c|c|}
\hline $\begin{array}{l}\text { Nombre } \\
\text { del proyecto }\end{array}$ & $\begin{array}{l}\text { Organizaciones } \\
\text { intervinientes }\end{array}$ & Tipo & Características \\
\hline $\begin{array}{l}\text { Especialización e } \\
\text { Inserción laboral }\end{array}$ & $\begin{array}{l}\text { Escuela de suboficiales } \\
\text { de la Armada (ESA) y la } \\
\text { Municipalidad (MUNI). }\end{array}$ & $\begin{array}{l}\text { Educativo, } \\
\text { Formación } \\
\text { Profesional }\end{array}$ & $\begin{array}{l}\text { Convenio de colaboración } \\
\text { para brindar capacitaciones } \\
\text { en diversos temas de interés. } \\
\text { El municipio detecta necesi- } \\
\text { dades en la comunidad y la } \\
\text { ESA capacita haciendo uso de } \\
\text { recursos técnicos y humanos. }\end{array}$ \\
\hline $\begin{array}{l}\text { Plan director } \\
\text { de obra de } \\
\text { infraestructura } \\
\text { eléctrica }\end{array}$ & $\begin{array}{l}\text { Cooperativa Eléctrica (CEPA) } \\
\text { y la MUNI }\end{array}$ & Infraestructura & $\begin{array}{l}\text { Mantenimiento de la infraes- } \\
\text { tructura eléctrica de Punta } \\
\text { Alta y localidades aledañas en } \\
\text { base al establecimiento } \\
\text { de prioridades conjuntas. }\end{array}$ \\
\hline $\begin{array}{l}\text { Expansión y } \\
\text { aprovechamiento } \\
\text { de los diques secos }\end{array}$ & $\begin{array}{l}\text { Base Naval Puerto Belgra- } \\
\text { no (BaseNaval), MUNI y la } \\
\text { Cámara de Talleres Navales } \\
\text { (CTNaval) }\end{array}$ & Productivo & $\begin{array}{l}\text { Reactivación de la capacidad } \\
\text { operativa de un dique de ca- } \\
\text { rena situado en la Base Naval } \\
\text { para fines comerciales. }\end{array}$ \\
\hline Acceso al Crédito & $\begin{array}{l}\text { Cámara de mujeres empresa- } \\
\text { rias (CMEmpres) con el Banco } \\
\text { Provincia (BcoPCIA) y el Banco } \\
\text { Nación (BcoNACION) }\end{array}$ & Financiamiento & $\begin{array}{l}\text { Coordinar y facilitar el acceso } \\
\text { al crédito de las emprendedo- } \\
\text { ras en dependencias de tales } \\
\text { entidades crediticias. }\end{array}$ \\
\hline
\end{tabular}

Fuente: Elaboración propia en base a entrevistas. 
Tal y como puede observarse en la tabla, el total de proyectos declarados fue tan sólo de 4 (cuatro), siendo las categorías educativo, de infraestructura, productivo y de financiamiento. Por su parte, el siguiente gráfico muestra los lazos nacidos a través de trabajos de colaboración entre las organizaciones estudiadas (Figura 2).

\section{Figura 2.}

Lazos entre organizaciones a partir de proyectos económicos conjuntos

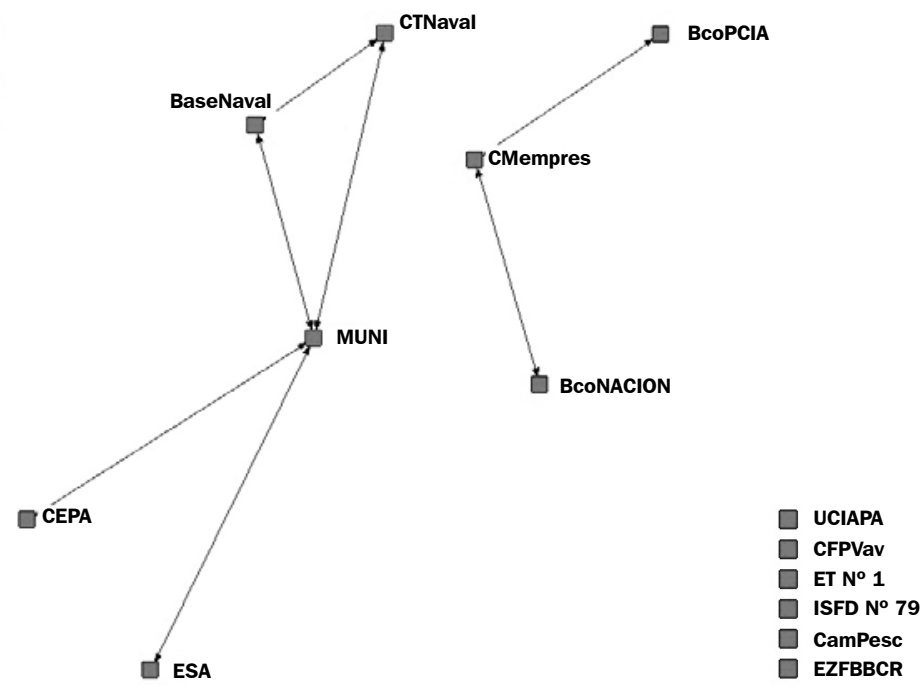

Fuente: Elaboración propia en base a entrevistas

Este tipo de redes se denomina redes de afiliación o de implicancia mutua (Waserman y Faust, 1994) porque el vínculo se establece cuando ambas organizaciones declaran estar efectuando un proyecto. Como puede apreciarse en la Figura 2, solo 8 organizaciones de las 14 estudiadas en este trabajo comparten iniciativas de estas características, existiendo 6 entidades que manifestaron no desarrollar acciones cooperativas de esta naturaleza.

Evaluando con mayor detalle el nivel de participación de las entidades en este tipo de propuestas, resulta necesario destacar que la entidad que más proyectos manifestó tener fue la Municipalidad de Coronel Rosales (MUNI) con 
un total de 3 (tres). Esta situación se encuentra en sintonía con lo establecido en la teoría de redes, que sostiene que instituciones con estructuras organizativas más complejas suelen tener mayor cantidad de proyectos de colaboración que aquellas con formas organizacionales más simples.

Con posterioridad, se indago a los representantes de las entidades entrevistadas respecto a cuáles eran, a su juicio, las causas que limitan o condicionan la realización de acciones de colaboración (Cuadro 10).

\section{Cuadro 10.}

Causas que limitan la realización de proyectos

\begin{tabular}{lcr}
\hline Por qué no desarrollan más proyectos conjuntos & Frecuencia & Porcentaje \\
\hline Política institucional centrada en resolver problemas propios & 12 & 21,82 \\
Recursos económicos limitados & 11 & 20,00 \\
Falta de áreas de comunicación institucional o vinculación & 9 & 16,36 \\
Ausencia de formación en temas de vinculación & 8 & 14,55 \\
Falta de programas nacionales que alienten estas prácticas & 7 & 12,73 \\
Diferencia de intereses entre organizaciones & 4 & 7,27 \\
Falta de interés en compartir conocimientos & 2 & 3,64 \\
No sabe / No contesta & 2 & 3,64 \\
Total & $\mathbf{5 5}$ & $\mathbf{1 0 0 , 0 0}$ \\
\hline
\end{tabular}

Fuente: Elaboración propia en base a entrevistas

En orden de importancia la primer causa manifestada por los entrevistados fue la existencia de una política institucional demasiado focalizada en resolver problemas propios (12 menciones). En este sentido, los entrevistados sostienen que las entidades priorizan solucionar situaciones que hacen a garantizar el normal desenvolvimiento de los senvicios esenciales que brinda la organización, por sobre cualquier otro tipo de esfera de actuación.

En segundo lugar, se destaca la falta de recursos económicos (11 menciones). La gran mayoría de las entidades sostiene que las limitaciones presupuestarias constituyen un condicionante a la hora de iniciar actividades de colaboración: de hecho, resulta habitual que no cuenten con partidas destinadas a tal efecto.

En tercer y cuarto término, se mencionan como condicionantes la falta de áreas de comunicación o vinculación institucional (9 menciones) y la ausencia 
de personal formado en dicha temática (8 menciones). En relación a este punto, los entrevistados son conscientes que una mejor articulación requiere el desarrollo de áreas específicas de trabajo y personal formado. Esto incluye habilidades para producir documentos específicos de difusión y para diseñar y evaluar iniciativas adecuándolas a determinados estándares. También supone el manejo de lenguaje y vocabulario específico, capaz de acercar a organizaciones que presentan objetivos diferentes.

En quinto lugar, los entrevistados destacan como un limitante la falta de programas nacionales que alienten este tipo de prácticas (4 menciones) Bajo su punto de vista, serviría como aliciente para impulsar el desarrollo de estrategias cooperativas la existencia de políticas específicas que de algún modo las induzcan, en contextos en los cuales estas prácticas no están demasiado arraigadas.

Finalmente, reconocen como restricciones a la cooperación la presencia de diferentes intereses en las organizaciones y la falta de vocación para compartir conocimientos (4 y 2 menciones respetivamente). Aquí se sostiene que las entidades no son proclives a colaborar si creen que esto puede provocar la pérdida del monopolio en la representatividad de un sector o de un determinado knowhow - expertice - que ostentan en la comunidad.

\section{LIDERAZGOS}

Entre los principales referentes de la economía regional, Utria (1981) plantea como un elemento fundamental de las posibilidades de desarrollo territorial el grado de organización existente en una comunidad.

Según el autor, una sociedad dinámica que experimenta un cambio activo a favor del desarrollo contiene en su seno una dosis de conflicto y de puja de intereses, pero en la búsqueda del progreso social y económico la población debe estar integrada, para asegurar un grado razonable de acuerdo y de unidad de acción.

Desde esta visión, resulta de suma importancia el papel que juegan las organizaciones territoriales y sus líderes como catalizadores y guías de la ciudadanía, capaces de impulsar una estrategia que contenga y sintetice diferentes aspiraciones.

Esta perspectiva supone que cuanto más eficiente es la organización del territorio y genuino el liderazgo institucional, más está la comunidad local en condiciones de desempeñar un papel activo y eficiente en las tareas del desarrollo. 
Para intentar evaluar la presencia o ausencia de liderazgos de esta naturaleza, D'Annunzio (2000), Costamagna (2000) y Ferraro y Costamagna (2002) desarrollaron una metodología que permite el estudio de cuatro puntos claves para el desarrollo económico territorial.

Esta consiste en instar a los referentes locales a nombrar de manera objetiva a tres agentes que consideran líderes en cuatro temas, existiendo la posibilidad de auto evaluación. Los temas a considerar son los siguientes:

- Generación de iniciativas y propuestas.

- Capacidad para articular y generar consenso entre las distintas entidades.

- Capacidad de negociación con actores externos al ámbito local.

- Visión Estratégica de Futuro respecto a temas vinculados al desarrollo económico del territorio en cuestión.

En el caso del indicador "Generación de Iniciativas y Propuestas", los resultados reflejan que UCIAPA (31\%) es la organización que lidera este segmento, secundados por la Municipalidad (MUNI) $(26,20 \%$ ) y la Cooperativa eléctrica (CEPA) $(21,40 \%)$. Las restantes organizaciones adquieren valores que no resultan ser significativos (Gráfico 1).

\section{Gráfico 1.}

Iniciativas y propuestas

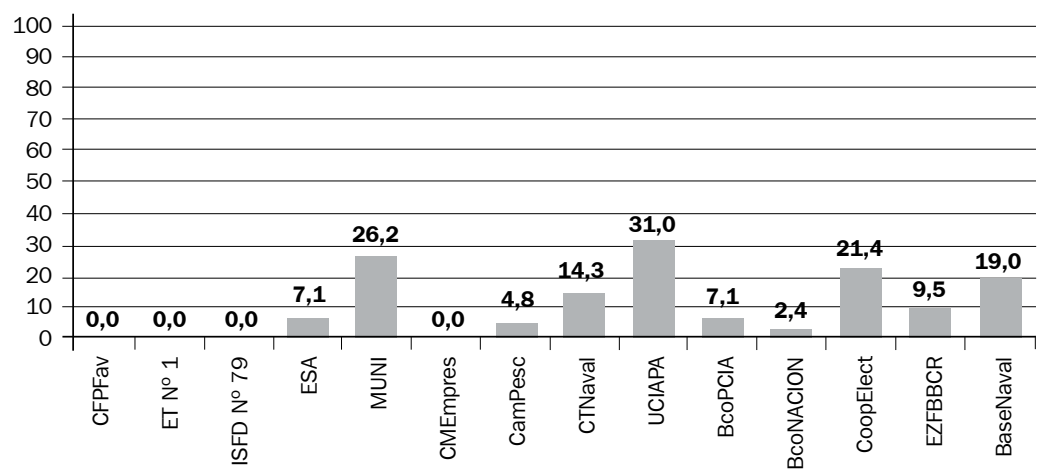

Fuente: Elaboración propia en base a entrevistas. 
Seguidamente el indicador "Capacidad para Articular y Generar Consenso" (Gráfico 2) muestra un ordenamiento similar al anterior, con el agregado de mayores diferencias entre las organizaciones líderes en este segmento y las demás: UCIAPA (50\%), MUNI (35,71\%), CEPA (23,81\%).

\section{Gráfico 2.}

Articulación y Generación de Consenso

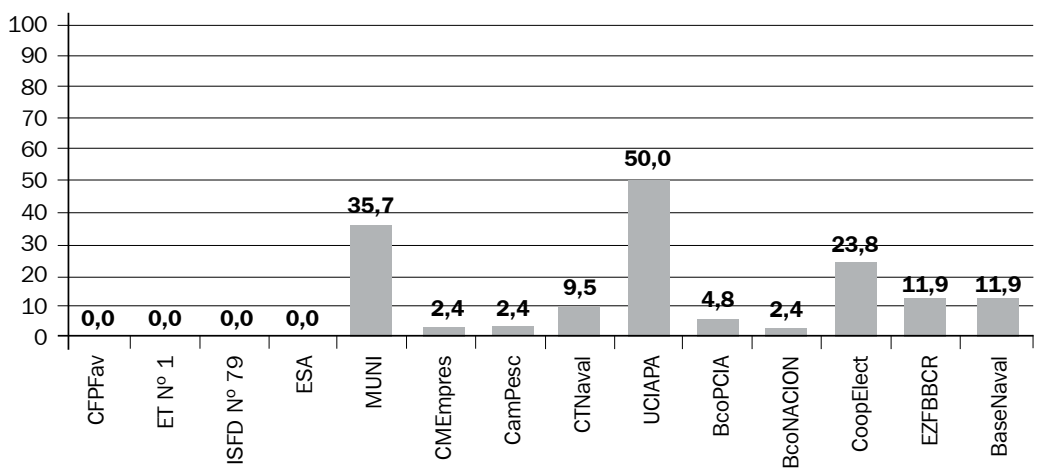

Fuente: Elaboración propia en base a entrevistas.

En tercer lugar, se relevó cuáles son aquellas organizaciones que tienen mayor "Capacidad de Negociación" (Gráfico 3). Estas son nuevamente UCIAPA (57,14\%) y MUNI (26,19\%), seguidas en este caso por EZFBBCR $(19,05 \%)$.

En cuarto término, el indicador "Visión Estratégica de Futuro" vuelve a colocar a los tres primeros actores enunciados en este apartado obteniendo los valores más altos del índice (Gráfico 4). Aquí aparece liderando UCIAPA $(45,24 \%)$ seguido en orden de importancia por MUNI $(28,57 \%)$ y CEPA $(21,43 \%)$ respectivamente. 
Gráfico 3.

Capacidad de Negociación

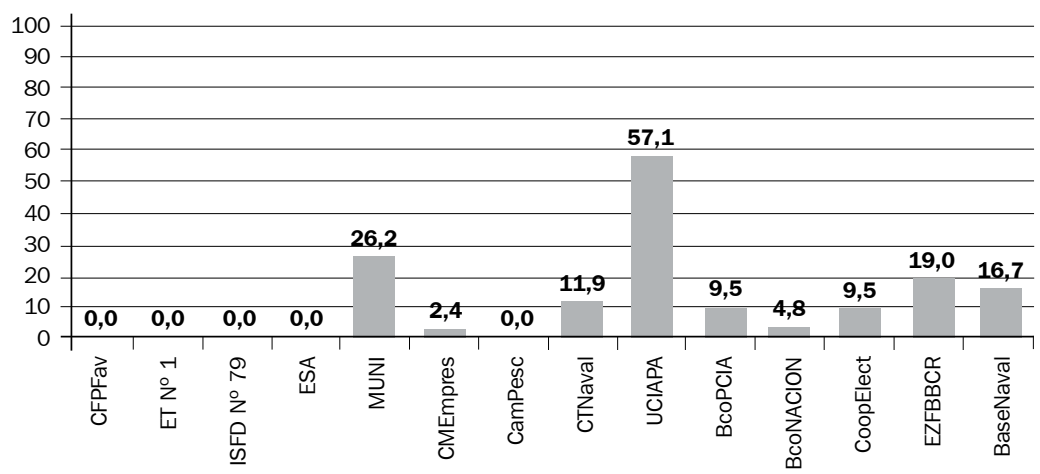

Fuente: Elaboración propia en base a entrevistas.

Gráfico 4.

Visión Estratégica

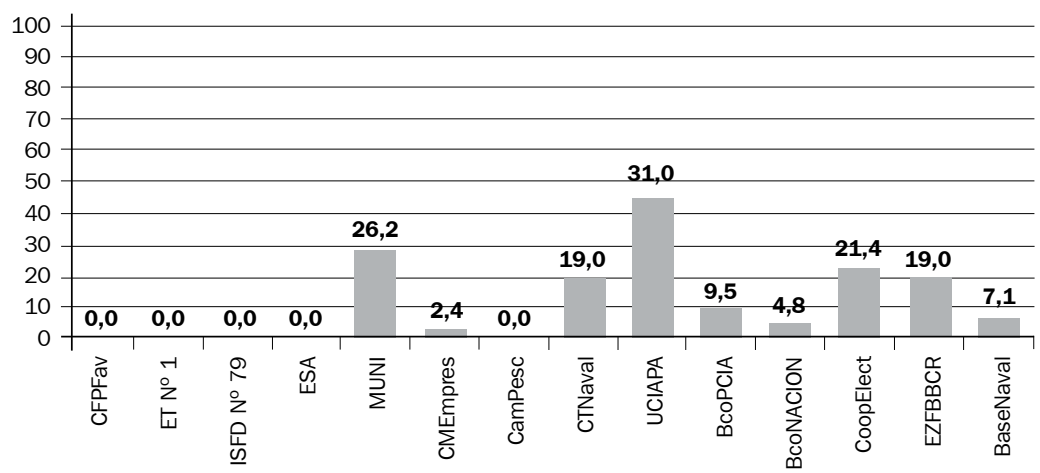

Fuente: Elaboración propia en base a entrevistas. 


\section{CONCLUSIONES}

En el ámbito de la geografía y de la economía urbana y regional, existe un creciente interés en el papel que pueden jugar las ciudades pequeñas y medias como instrumentos capaces de favorecer el desarrollo de sistemas urbanos más equilibrados.

Entre los elementos claves que permiten el crecimiento y consolidación de estos núcleos poblacionales se encuentran las redes institucionales. Estas redes son un insumo básico para la promoción de la competitividad urbana, ya que incentivan la transformación económica y social de los territorios.

Como bien sostienen Michellini y Davies (2009), los actores institucionales — públicos y privados - juegan un rol significativo en el desarrollo de una localidad. Las características y la capacidad de coordinación del contexto institucional (Amin y Thrift, 1995), en función de proyectos concretos y de una visión de futuro del territorio, constituyen frecuentemente un rasgo distintivo de sus potencialidades.

A su vez, en el contexto actual de la economía mundial, la capacidad de dichas entidades para aprender de los cambios en el entorno y generar y difundir conocimiento en el ámbito local —social u empresarial—, es un elemento destacado en la literatura como incentivador del crecimiento y la acumulación de capital.

En el caso particular de la localidad de Punta Alta, puede observarse que las organizaciones presentan dificultades para comunicarse adecuadamente. De acuerdo a los datos suministrados por los entrevistados, sólo están presentes un 31\% de los intercambios de información posibles (densidad de comunicaciones baja), lo cual muestra la presencia de importantes orificios estructurales en la red.

En este sentido, existe un $69 \%$ de comunicaciones ausentes, lo que evidencia que la información y el conocimiento no circula de forma fluida en el sistema considerado.

Estas limitaciones en los procesos de intercambio de conocimientos e información se traducen en una pobre cantidad de proyectos conjuntos, existiendo tan sólo un total de 4 .

Esta cantidad puede ser considerada baja si se lo compara con estudios de similares características desarrollados sobre otras ciudades del sudoeste de la provincia de Buenos Aires ${ }^{11}$.

Además existe un número importante de organizaciones (6, un $43 \%$ del universo estudiado) que se encuentran completamente desarticuladas del resto del entramado en lo concerniente al desarrollo de actividades de colaboración, lo cual muestra un integración institucional muy débil. 
De este modo, la evidencia recogida parece respaldar lo sostenido por la teoría de redes, de que existe una correlación positiva entre lazos de comunicación y acciones conjuntas: a mayor cantidad de transmisión de información entre los agentes, más proyectos, registrándose a su vez la relación inversa. Pocos contactos traen como correlato pocas acciones de colaboración.

A su vez, los actores territoriales identifican como limitantes para el desarrollo de iniciativas de estas características una serie de factores, entre los que se destacan: $1^{\circ}$ ) La política institucional demasiado focalizada en atender problemas propios; $2^{\circ}$ ) La falta de recursos económicos; $3^{\circ}$ ) Un limitado desarrollo de las áreas de vinculación.

En función de estos resultados, puede asegurarse que la incidencia que tiene el entramado institucional de apoyo a la producción sobre las posibilidades de desarrollo del territorio en cuestión es poco significativa, en consonancia con otros resultados encontrados para otras localidades del sudoeste de la Provincia de Buenos Aires y de Argentina.

Sin embargo, un análisis más pormenorizado del papel de cada uno de los actores entrevistados, permite identificar aquellos agentes con mayor y menor capacidad para alterar la dinámica institucional observada.

Retomando el análisis sobre la red comunicaciones (Figura 1), un estudio a nivel micro de la misma permite reconocer que actores resultan centrales dentro del esquema de comunicacional vigente.

En función de los diversos indicadores construidos para el estudio de esta red (grado de centralidad, centralidad de cercanía y grado de intermediación) pueden reconocerse al menos tres instituciones con cierta incidencia en el agrupamiento estudiado: Municipalidad de Coronel Rosales (MUNI), Banco Provincia de Buenos Aires (BcoPCIA), Unión del Comercio, la industria y el Agro de Punta Alta (UCIAPA).

Estos actores tienen una importante incidencia en el envío y la recepción de información y cuentan con una importante capacidad de intermediación: MUNI controla el $29 \%$ de los conocimientos que circulan en el sistema, mientras UCIAPA y BcoPCIA controlan el 19 y el $10 \%$, respectivamente.

De estos tres agentes, solo MUNI y UCIAPA logran transformar su importante predicamento en un liderazgo genuino en los cuatro ítems estudiados: Generación de Iniciativas y Propuestas, Articulación y Generación de Consenso, Capacidad de Negociación y Visión Estratégica de Futuro.

En el caso de MUNI su liderazgo parece estar cimentado en la participación en proyectos colaborativos, ya que es la entidad que más articula con el resto en este sentido, participando en tres de los cuatro proyectos registrados. 
Por su parte, esta no parece ser la situación de UCIAPA, ya que no desarrolla actividades de colaboración con el resto de los agentes del entramado y sin embargo es reconocida como una entidad de relevancia.

Finalmente, cabe mencionar el caso de la Coop. Elect-CEPA (Cooperativa Eléctrica de Punta Alta). Esta organización, pese a no tener un rol significativo en la emisión, recepción o intermediación de información, es reconocida por los actores locales como un agente significativo en los procesos de desarrollo económico local.

De acuerdo a lo manifestado por los entrevistados, esto se debe a que gran parte de la infraestructura construida en la ciudad es impulsada y promovida por esta institución.

De este modo, puede decirse que cualquier política pública que busque incentivar el trabajo colaborativo y la conformación de redes de promoción del desarrollo, deberá considerar el papel que hoy día juegan los actores anteriormente enunciados en el andamiaje institucional local.

Se esperaría que una política de esta naturaleza fuese impulsada desde el gobierno local y en consenso con los actores territoriales, aunque también podría ser promovida de ser necesario "desde arriba" por esferas gubernamentales provinciales o nacionales.

Será entonces necesario diseñar mecanismos que permitan involucrar más eficientemente a estos actores en el diseño de estrategias colaborativas, de forma tal de nutrirse más efectivamente de sus capacidades, competencias y habilidades. A partir de un accionar de esta naturaleza, se generarán condiciones objetivas para una mayor y mejor difusión de conocimientos e innovaciones, que impacten positivamente sobre el crecimiento económico del territorio. 


\section{NOTAS}

1 Por atractividad se entiende la capacidad de una localidad para captar inversiones externas directas mientras que el concepto de fertilidad remite a las competencias que un territorio tiene para incentivar el nacimiento de empresas de capital local.

${ }^{2}$ Las entrevistas se basaron mayormente en un conjunto de preguntas semi estructuradas, que incluía tanto preguntas cerradas como abiertas. La técnica utilizada fue de embudo, es decir que se ordenaron las preguntas desde aquellas más generales hacia las más concretas u específicas (Vieytes, 2004).

3 Específicamente se utilizan los programas UCINET 6.45 y Netdraw 2.12.

4 Entre los años 2000 y 2002, la Comisión Económica para América Latina y el Caribe desarrollo estudios sobre densidad institucional en las localidades de Rafaela, Tandil y Mar del Plata. 5 Para el caso argentino, no existe un criterio único que delimite adecuadamente que se entiende por ciudad pequeña o media. Para Sassone (1992; 2000), constituyen ciudades pequeñas aquellas que oscilan entre los 5000 y los 20.000 habitantes, mientras que una ciudad media oscilaría entre 20.000 y 500.000 personas.Para Vapñarsky (1995; 2004) el límite superior para una ciudad pequeña debe extenderse necesariamente hasta una población que ronde las 60.000 personas, mientras que entre 60.000 y 600.000 habitantes estaríamos hablando de una ciudad de tamaño medio. Debido a esta cuestión, el criterio que se utiliza para calificar a estos núcleos urbanos está más ligado a su funcionalidad (principalmente económica) dentro del sistema urbano nacional que a la densidad demográfica. ${ }^{6}$ Los límites de crecimiento (en Inglés TheLimit of Growth) es un informe encargado al MIT por el Club de Roma. El mismo fue publicado en 1972, pocos años antes de la crisis del petróleo. El informe se basa en la simulación informática del programa World3, el cual recrea el crecimiento dela población, el crecimiento económicoy el incremento de la huella ecológica de la población sobre la tierra en los próximos 100 años, según los datos disponibles hasta la fecha. La tesis principal del libro es que, "en un planeta limitado, las dinámicas de crecimiento exponencial (población y producto per cápita) no son sostenibles". Así, el planeta pone límites al crecimiento, como los recursos naturales no renovables, la tierra cultivable finita, y la capacidad del ecosistema para absorber la polución producto del quehacer humano, entre otros. Estos resultados tuvieron un fuerte impacto en diversas disciplinas, entre ellas la geografía y la economía, permitiendo incorporar a distintas teorías la noción de desarrollo sostenible o sustentable.

7 Existen muchas menciones de organismos y organizaciones internacionales respecto a la necesidad de promover sistemas urbanos más equilibrados. A modo de ejemplo, la Comisión Europea propuso en el año 1999 el policentrismo como solución al desarrollo regional europeo, ya que este daría mayor cohesión a las regiones. En dicho informe se destaca el papel de las ciudades pequeñas y medias como elementos estructurantes del territorio (Faludi, 2005).

8 La idea de optimizar el uso de los recursos propios para promover el crecimiento y la acumulación de capital se encuentra bien formulada en el enfoque del desarrollo endógeno (Vázquez Barquero, Boisier, Alburquerque, Arocena, entre otros).

${ }^{9}$ El enfoque de centralidad de cercanía se utiliza habitualmente en matrices simétricas, pero UCINET permite calcular la medida para matrices normales diferenciando entre cercanía por lazos de entrada y cercanía por lazos de salida.

${ }^{10}$ La clasificación de proyectos económicos se divide en: productivos (se separan en extractivos y de transformación); capacitación; prestación de servicios (organizativos, institucionales, financieros y tecnológicos) y de infraestructura y equipamiento.

11 Para la ciudad de Bahía Blanca, Diez (2010) encontró un total de 46 proyectos de colaboración sobre un total de 33 entidades de apoyo a la producción entrevistadas. Por su parte, Diez y Urtizberea(2015) en su estudio sobre la localidad de Pigué encontraron un total de 19 proyectos cooperativos para un total de 16 entidades entrevistadas. 


\section{BIBLIOGRAFÍA}

Amin, A. y Thrift, N. (1995). "Institutional issues for the European Regions: from markets and plans to socioeconomics and power of association" Economy and Society, 24 (1), pp 41-66. Disponibleendoi: 10.1080/03085149500000002 (Consultado 28/08/2017).

Bennett, R. y Krebs, G. (1994). "Local economic development partnerships: an analysis of policy networks in ECLEDA local employment development strategies" Journal of Regional Studies, 28 (2), pp 119-140.

Best, M. (1990). The New competition. Institutions of industrial restructuring. Cambridge: Polity Press. Disponible en http://journals.sagepub.com/doi/abs/10.1177/017084069301400417 (Consultado 09/09/2017).

Boisier, S. (1997). «El vuelo de una cometa. Una metáfora para una teoría del desarrollo territorial", Serie Ensayos Instituto Latinoamericano y del Caribe de Planificación Económica y Social, Documento 97/37. Santiago de Chile: ILPES. Disponible en http://www.upo.es/ghf/ giest/ODTA/documentos/MarcoTeorico/ILPES/boisier_destet.pdf (Consultado 01/09/2017).

Borgatti, S.P., Everett, M.G. y Freeman, L.C. (2002). Ucinet for Windows: Software for Social Network Analysis. Harvard, MA: Analytic Technologies.

Boudeville, J. (1965). Los espacios económicos. Buenos Aires: EUDEBA.

Camagni, R. (1991). Innovation networks. Spatial perspectives. Londres: BelhavenPress.

Caravaca, I., González, G. y Silva, R. (2005). «Innovación, redes, recursos patrimoniales y desarrollo territorial» Revista EURE (Revista De Estudios Urbano Regionales), 31 (94), pp 5-24. Disponible en http://www.eure.cl/index.php/eure/article/view/1332 (Consultado 25/08/2017).

Capel, H. (2009). "Las pequeñas ciudades en la urbanización generalizada y ante la crisis global» Investigaciones Geográficas, Boletín del Instituto de Geografía, UNAM (70), pp 7-32. Disponible en http://www.igeograf.unam.mx/sigg/utilidades/docs/pdfs/publicaciones/inves_geo/ boletines/70/b70_art549.pdf (Consultado 29/09/2017).

Costamagna, P. (2000). «La articulación y la interacción entre instituciones: la iniciativa de desarrollo económico local de Rafaela, Argentina». Proyecto CEPAL/GTZ, Desarrollo Económico Local y Descentralización en América Latina. Santiago de Chile:NacionesUnidas. Disponible en http://www.aguaycambioclimatico.info/biblioteca/DEL_0156.pdf (Consultado 20/09/2017).

Costamagna, P., Ferraro, C. Gor, E. (2005). Análisis del funcionamiento y la articulación del entramado institucional de apoyo a la producción: el caso Bragado. Bragado: UNNOVACEPAL-GTZ.

Costamagna, P. (2008). «Las organizaciones del territorio. Cambios para fortalecer el desarrollo territorial». Revista OIDLES, 1 (3), pp. 1-16. Disponible en: http://www.eumed.net/rev/ oidles/03/Costamagna.htm. (Consultado 13/03/2018). 
Diez, J.I. (2010). Desarrolloendógeno en Bahía Blanca: empresas, organizaciones y políticaspúblicas. BahíaBlanca:EdiUNS.

Diez, J.I. y Urtizberea, N. (2015). "Redes institucionales y desarrollo económico en ciudades pequeñas: el caso de la localidad de Pigué». Revista EURE (Revista De Estudios Urbano Regionales), 41 (123), pp 265-289. Disponible en http://www.eure.cl/index.php/eure/article/ view/580/820 (Consultado 08/09/2017).

D’Annuzio, C. (2000). «Iniciativa de Desarrollo Económico Local. La articulación y las interacciones entre instituciones: el caso Tandil Argentina». Proyecto CEPAL/GTZ, Desarrollo Económico Local y Descentralización en América Latina. Santiago de Chile: Naciones Unidas. Disponible en http://biblioteca.municipios.unq.edu.ar/modules/mislibros/archivos/tandil.pdf (Consultado 03/09/2017).

Dominguez Ares, E. (1999). Las organizaciones como instrumento de desarrollo local. Trabajo Profesional Fin de Carrera (inédito), Escuela Técnica Superior de Ingenieros Agrónomos y de Montes Universidad de Córdoba España.

Erbiti, C. (2004). Los condicionantes del desarrollo endógeno en las ciudades de la macroregión pampeana: el caso Tandil, Argentina, Tesis Doctoral (inédito). Facultad de Filosofía y Letras Universidad Autónoma de Madrid.

Faludi, A. (2005). "La política de cohesión territorial de la Unión Europea". Boletín de la Asociación de Geógrafos Españoles, (39), pp 11-30. Disponible en https://dialnet.unirioja. es/servlet/articulo?codigo =1161228 (Consultado 23/09/2017).

Ferraro, C. y Costamagna, P. (2002). "Competitividad territorial e instituciones de apoyo a la producción en Mar del Plata". CEPAL - SERIE Estudios y perspectivas, Buenos Aires: Oficina de la CEPAL. Disponible en http://repositorio.cepal.org/bitstream/handle/11362/4873/ S027494_es.pdf;jsessionid =863CECD7738F852DBC1A021CDE7158C6 sequence $=1$ (Consultado 30/09/2017).

Filippi, M. y Torre, A (2003). "L'organisation en réseau: de l'instauration de régles locales aux actions collectives" En: Dupuy, A. y Burmeister, A. (eds), Enterprises et territories. Les nouveaux enjeux de la proximité París: La documentation Francaise. Disponible en https:// www.andre-torre.com/pdf/PDFpub111N1.pdf (Consultado 07/09/2017).

Flores, F. (1989). Inventando la empresadelsiglo XXI. Santiago de Chile: Hachette.

Hanneman, R. (1998). Introducción a los métodos de análisis de redes sociales. California: Universidad de California Riverside.

Harrigan, K. (1992). JointVenture, Buenos Aires: Tesis-Norma.

Instituto Nacional de Estadística y Censos de la República Argentina (2010). Censo Nacional de Población y Vivienda. Buenos Aires: Ministerio de Economía. 
Instituto Latinoamericano de Planificación Económica y Social (1966). Discusiones sobre planificación. Santiago de Chile: Siglo XXI.

Martín, C. (2007). Industria, innovación y desarrollo territorial. Tres Arroyos, Argentina. Tesis Doctoral (inédito). Departamento de Geografía y Turismo Universidad Nacional del Sur.

Meadows, D. et al. (1973). Los límites del crecimiento. Boston: Massachusets Institute of Technology (MIT).

Méndez, R. (1997). Geografía económica. La lógica espacial del capitalismo global. Barcelona: Ariel, 1997.

(1998). «Innovación tecnológica y reorganización del espacio industrial: una propuesta metodológican. Revista EURE (Revista De Estudios Urbano Regionales), 24 (73), pp 31-54. Disponible en https://www.eure.cl/index.php/eure/article/view/1187/286 (Consultado 04/07/2017).

Michellini, J. y Davies, C. (2009). "Ciudades intermedias y desarrollo territorial: un análisis exploratorio del caso argentino". Documento de Trabajo № 5, Madrid: Grupo de Estudios sobre desarrollo urbano (GEDEUR). Disponible en http://cite.flacsoandes.edu.ec/media/2016/02/ Michelini__et_al_2009_Ciudades_intermedias_y_desarrollo_territorial_un_analisis_exploratorio_del_caso_argentino1-1.pdf (Consultado 18/09/2017).

Ministerio de Agroindustria de la República Argentina (2015). Caracterización de la producción Bovina. Buenos Aires: Ministerio de Agroindustria.

Morgan, G. (1986). Imágenes de las organizaciones. México D. F.: Alfaomega.

Paelinck, J. (1963). "La teoría del desarrollo regional polarizado", Revista de Economía Latinoamericana, 9 (15), pp 22-47.

Perroux, F. (1955). «Nòte sur la Notion de Pòle de Croissance». Economie Apliquée, 8 (17), pp 15-29.

Sassone, M.S. (1992). "Subsistemasurbanospolicéntricos en los sistemasnacionales de ciudades. Un caso en la Argentina». RevistaGeográfica, (116), pp 85-111.

(2000). «Reestructuración territorial y ciudadesintermedias en Argentina». Ciudad y Territorio. Estudios Territoriales, 32 (123), pp 57-92.

Schulz, C. J. (2004). Estudiohidrogeólogicodelárea centraldel Valle Argentino en La Pampa (Argentina). Tesis para acceder al Doctorado en Geología (ínedito). UniversidadNacional de Córdoba. 
Utria, R. (1981). "Algunos aspectos sociales del desarrollo regional en América Latina" En: Kuklinski, A. (comp.), Aspectos sociales de la Política y de la Planeación Regional. Distrito Federal México: Fondo de Cultura Económica.

Vapñarsky, C. (1995). «Primacía y macrocefalia en Argentina: la transformación del sistema de asentamiento humano desde 1950". Desarrollo Económico, 35 (138), pp 227-254.

(2004). "Cuando el caoscaracteriza la divisiónoficialdelterritoriodelEstado. A propósito de los municipiosargentinos». Scripta Nova, 8 (162). Disponible en http://www.ub.edu/geocrit/ sn/sn-162.htm (Consultado 25/09/2017).

Vázquez Barquero, A. (2001). Desarrolloendógeno y Globalización. En : VázquezBarquero, A. y Madoery, O. (comp.), Transformaciones globales, instituciones y políticas de desarrollo local. Rosario: Homo Sapiens. Disponible en https://www.institutodeestudiosglobales.org/ resources/Desarrollo\%20end\%C3\%B3geno\%20y\%20globalizaci\%C3\%B3n.pdf (Consultado 19/09/2017).

Vieytes, R. (2004). Metodología de la investigación en organizaciones, mercado y sociedad. Epistemología y técnicas. Buenos Aires: Editorial de las Ciencias.

Wasserman, S., Faust, K. (1994). Social Network Analysis. Methods and Applications. Cambridge: Cambridge UniversityPre

\section{PARA CITAR ESTE ARTÍCULO:}

Diez, J.I.; Lencina, E.; Pong, C. (2018). «Redes institucionales y desarrollo económico en ciudades pequeñas y medias: el caso de la localidad Punta Alta", DAAPGE, año 18, № 30 (ene-jun), 2018, pp. 7-41. Santa Fe, Argentina: UNL. 